\title{
Discursos sobre o currículo oficial do estado de São Paulo no contexto de um curso de formação continuada para professores de Física
}

\author{
Discourses about the official curriculum adopted \\ by the state of São Paulo in the context of a continuing \\ education for physics' teachers
}

Marcelo Zanotello ${ }^{1}$. Marcelo Oliveira da Costa Pires ${ }^{1}$

\begin{abstract}
Resumo: Neste artigo, estudamos discursos sobre o currículo oficial do Estado de São Paulo para a disciplina de Física, com base no referencial sobre currículo elaborado por Gimeno Sacristán e na perspectiva teórica da Análise de Discurso (AD) francesa. Na pesquisa de natureza qualitativa, foram analisados documentos oficiais que compõem o currículo e discursos de 23 professores de Física da rede pública de ensino no contexto de um curso de formação continuada. Os posicionamentos dos professores evidenciam ações modeladoras que eles exercem sobre o currículo prescrito, com reflexos diretos em suas práticas pedagógicas. O curso propiciou reflexões críticas sobre dificuldades que esse grupo de professores enfrenta no trabalho nas escolas em relação ao currículo que lhes é apresentado. As análises indicam que uma possibilidade para promover uma formação continuada significativa aos professores consiste em propiciar condições para a constituição de discursos que sejam menos autoritários e mais polêmicos.
\end{abstract}

Palavras-chave: Discurso. Currículo. Formação continuada de professores. Ensino de Física.

\begin{abstract}
In this article, we study discourses about the official curriculum adopted by state of Sao Paulo for the area of physics. We based it on Gimeno Sacristan's analysis about the curriculum and within the theoretical perspective of French Discourse Analysis. In this qualitative research official documents that make up the curriculum were analysed and the discourses of 23 physics teachers from state schools in the context of a continuing education program. Teachers' discourses show their actions on the prescribed curriculum, with direct consequences on their teaching practices. The program provided critical reflections about the difficulties of this group of teachers in their work in schools in relation to the curriculum that is presented to them. The analyzes indicate that a possibility to promote a significant continuing education for teachers is provided by conditions for the formation of pedagogical discourses that are less authoritarian and more controversial.
\end{abstract}

Keywords: Discourses. Curriculum. Teachers' continuing education. Physics teaching.

\footnotetext{
${ }^{1}$ Universidade Federal do ABC (UFABC), Centro de Ciências Naturais e Humanas (CCNH), Santo André, SP, Brasil. E-mail: <marcelo.zanotello@ufabc.edu.br>
} 


\section{Introdução}

Ao realizar uma revisão de diferentes abordagens sobre currículo, Silva (2010) identifica duas questões centrais e recorrentes. A primeira consiste na definição de quais os conhecimentos a serem ensinados, o que implica, explícita ou implicitamente, no desenvolvimento de critérios de seleção que justifiquem a inserção de determinados conhecimentos no corpo curricular. Relacionada a essa primeira questão, está outra pergunta fundamental: o que se almeja que as pessoas que seguirão certo currículo se tornem? De algum modo, se deduz o tipo de conhecimento tido como importante a partir da definição de atributos considerados ideais que as pessoas deveriam adquirir no período de escolarização. Dessa forma, estão envolvidos aspectos subjetivos que serão abarcados pelos autores de teorias e de propostas curriculares, e, na medida em que os atos de selecionar e de destacar, entre várias possibilidades, uma identidade como sendo a ideal se constituem em operações de poder, as teorias e propostas curriculares podem ser situadas em um campo epistemológico social (SILVA, 2010).

Ao nos propormos a estudar discursos sobre o currículo oficial do Estado de São Paulo para as Ciências da Natureza e suas Tecnologias, mais especificamente para a disciplina de Física, buscamos compreender alguns aspectos de sua concepção e funcionamento em situações práticas. Para tanto, nos basearemos em determinada visão sobre currículo e em um referencial considerado adequado para leitura de discursos referentes a esse currículo: o enfoque sobre currículo elaborado por Gimeno Sacristán (2000) e a vertente francesa da análise de discurso, desenvolvida, sobretudo, por Michel Pêcheux e amplamente divulgada no Brasil por Eni Orlandi (2010).

Nesta investigação de natureza qualitativa analisam-se documentos oficiais que constituem o currículo oficial do Estado de São Paulo (SÃO PAULO, 2010) e colocações de professores de Física da rede estadual paulista em um curso de formação continuada. As questões de pesquisa que nos motivam são as seguintes: Quais sentidos os professores de Física em atividade nas escolas públicas atribuem ao currículo oficial do Estado de São Paulo? Como se desenvolve a prática deste currículo no âmbito deste grupo de professores? Como um curso de formação continuada pode promover uma leitura crítica e propositiva para a prática docente mediante tal currículo?

\section{Um referencial sobre currículo}

Nossa escolha pela perspectiva sobre currículo de acordo com as ideias de Gimeno Sacristán (2000) se deve à ênfase dada por ele à relação entre o currículo e as práticas pedagógicas, bem como à complexidade e diversidade de fatores envolvidos na elaboração e desenvolvimento dos currículos, que vão além dos inerentes à sala de aula.

O currículo é definido como um "projeto seletivo de cultura, cultural, social, política e administrativamente condicionado que preenche a atividade escolar e que se torna realidade dentro das condições da escola tal como se acha configurada" (GIMENO SACRISTÁN, 2000, p. 34).

Por esta definição, considera-se que "em um currículo se entrecruzam componentes e determinações muito diversas: pedagógicas, políticas, práticas administrativas, produtivas de 
diversos materiais, de controle sobre o sistema escolar, de inovações pedagógicas, etc" (GIMENO SACRISTÁN, 2000, p. 32). Assim, um currículo não pode ser entendido à parte do contexto no qual se configura e independentemente das condições em que se desenvolve, caracterizando-se como um objeto social e histórico.

A partir desta concepção, Gimeno Sacristán (2000) propõe um modelo composto por seis fases ou níveis de desenvolvimento, que visam propiciar um entendimento da dinâmica curricular conforme sintetizado no Quadro 1. Tais fases têm inter-relações recíprocas, com diferentes graus de influência entre si.

Quadro 1. Níveis de desenvolvimento curricular e suas principais características, conforme Gimeno Sacristán (2000)

\begin{tabular}{|l|l|}
\hline \multicolumn{1}{|c|}{ Níveis } & \multicolumn{1}{c|}{ Características } \\
\hline Currículo prescrito & $\begin{array}{l}\text { Consequência das regulações às quais o sistema educativo está submetido. São } \\
\text { aspectos que atuam como referência na ordenação do sistema curricular; ponto } \\
\text { de partida para elaboração de materiais, controle do sistema etc. A política em } \\
\text { cada momento gera esquemas variáveis de intervenção e prescrição curricular. }\end{array}$ \\
\hline $\begin{array}{l}\text { Currículo } \\
\text { apresentado aos } \\
\text { professores }\end{array}$ & $\begin{array}{l}\text { Série de meios elaborados por diferentes instâncias que visam traduzir para os } \\
\text { professores o significado e os conteúdos do currículo prescrito, realizando uma } \\
\text { interpretação deste. }\end{array}$ \\
\hline $\begin{array}{l}\text { Currículo } \\
\text { modelado pelo } \\
\text { professor }\end{array}$ & $\begin{array}{l}\text { O professor é um agente ativo na concretização dos conteúdos e significados } \\
\text { dos currículos, moldando, a partir de sua cultura profissional e pessoal, } \\
\text { quaisquer propostas que lhe são feitas por meio de prescrições administrativas, } \\
\text { manuais didáticos etc. }\end{array}$ \\
\hline Currículo em ação & $\begin{array}{l}\text { É a prática real, constituída pelas ações pedagógicas que se concretizam nas } \\
\text { tarefas escolares. }\end{array}$ \\
\hline Currículo realizado & $\begin{array}{l}\text { Efeitos de diversos tipos (cognitivos, afetivos, sociais, morais etc.), produzidos } \\
\text { como consequência da prática, tanto nos professores quanto nos alunos. }\end{array}$ \\
\hline Currículo avaliado & $\begin{array}{l}\text { Pressões exteriores de diversos tipos sobre os professores ressaltam certos } \\
\text { aspectos na avaliação do currículo, coerentes ou incoerentes com os propósitos } \\
\text { manifestos por quem o elaborou e com os objetivos do professor. Abarcado } \\
\text { por procedimentos de avaliação variados, acaba impondo critérios para o ensino } \\
\text { do professor e aprendizagem dos alunos. }\end{array}$ \\
\hline
\end{tabular}

Fonte: adaptado de Capeloto e Zancul (2012).

O currículo prescrito constitui um modo que o Estado tem, organizado política e administrativamente em dado momento, de exercer sua hegemonia cultural, delineando as características de formação desejáveis e o perfil idealizado que as pessoas deveriam adquirir no período de escolaridade obrigatória. Numa perspectiva pedagógica mais específica, configura- 
se, também, como um meio para investigar o que ocorre na realidade escolar, uma vez que as determinações nele contidas afetam todos os demais níveis de desenvolvimento curricular.

Como as prescrições curriculares costumam ser genéricas, normalmente não são suficientes para orientar diretamente as atividades educativas nas aulas. Esta função é desempenhada por materiais instrucionais elaborados para que o professor possa, a partir deles, planejar e executar sua prática. O currículo apresentado ao professor se manifesta em manuais didáticos, livros-texto, apostilas etc., que podem ser produzidos por agentes privados ou por representantes do Estado.

Apesar de todas as determinações que recebe, o professor exerce ações modeladoras sobre o currículo ao realizar seu trabalho em sala de aula, estabelecendo uma relação que pode ser conflituosa entre o que é apresentado como ideal e um esquema de ensino que supostamente funciona para ele.

O professor, ao adotar uma nova ideia, o faz em função de seus próprios construtos pessoais e, ao desenvolver uma nova tarefa acadêmica, também a interpreta e a modela, por que nenhuma tarefa é um esquema tão acabado e inequívoco que não ofereça possibilidades para interpretação pessoal de cada professor, a partir de suas próprias finalidades e formas de perceber as demandas dos alunos e da nova situação. (GIMENO SACRISTÁN, 2000, p. 175)

Assim, o currículo se configura como um instrumento gerador de uma ampla gama de ações na escola, sendo um dos elementos fundamentais para se compreender a prática pedagógica. Relações entre prática e currículo podem ser estudadas a partir de análises das atividades realizadas para preencher o tempo escolar, uma vez que as tarefas desenvolvidas por professores e estudantes são o conteúdo da prática e constituem a realidade do currículo em ação.

A tarefa é o elemento intermediário entre as possibilidades teóricas que o currículo prescreve e os seus efeitos reais. Apenas através das atividades que são desenvolvidas podemos analisar a riqueza de uma determinada proposição curricular na prática. (GIMENO SACRISTÁN, 2000, p. 221)

O currículo realizado comporta uma série de efeitos complexos decorrentes da prática. Alguns desses efeitos são considerados rendimentos do sistema e dos métodos pedagógicos, refletindo-se em aprendizagens dos estudantes, enquanto outros ficam como efeitos ocultos do ensino por serem de difícil definição e de longo prazo. No currículo avaliado, resultados de atividades escolares são valorizados e mensurados em todos os níveis de escolaridade por mecanismos diversos que buscam avaliar tanto a aprendizagem dos estudantes quanto as instituições de ensino, mapeando e procurando regular a qualidade do ensino.

Neste trabalho, o currículo oficial do Estado de São Paulo para a disciplina de Física é analisado no âmbito de um curso de formação continuada para professores da rede pública paulista de ensino, considerando-se, sobretudo, as quatro primeiras fases do desenvolvimento curricular conforme o modelo de Gimeno Sacristán, em uma perspectiva sobre o funcionamento da linguagem de acordo com a Análise de Discurso em sua vertente francesa (ORLANDI, 2010). 


\section{Elementos da Análise de Discurso (AD) francesa}

Para a AD de linha francesa, discurso é definido como efeito de sentidos entre locutores, pressupondo a existência de um sistema significante (a linguagem) e a relação desse sistema com a exterioridade (ORLANDI, 2010). Além de suporte do pensamento e meio de transmissão de informação, a linguagem é considerada, sobretudo, produto do trabalho das pessoas num processo de interação social e histórico. Ela não é transparente, não existindo um sentido único a ser decodificado em um enunciado. Diante de um objeto simbólico, seja uma palavra, um texto, uma imagem ou uma equação, o ser humano é instado à interpretação. E as possibilidades de atribuição de sentidos no ato interpretativo são condicionadas pela história e pela ideologia.

A ideologia é entendida como o imaginário que medeia as relações do sujeito com suas condições de existência, permitindo uma relação entre pensamento, linguagem e mundo. Conforme Orlandi (1994), ao invés das características sociológicas empíricas (classe social, idade, sexo, profissão etc.), o que atua no discurso são as formações imaginárias que se constituem a partir das relações sociais (a imagem que se faz de um professor, de uma mãe, de um estudante, de um operário etc.). Nesta perspectiva, a interpretação se dá mediante condições de produção, que envolvem: os contextos histórico e social de formulação do discurso, os interlocutores (o autor e a quem ele se dirige), as posições em que os interlocutores se situam e em que são vistos, as imagens que fazem de si e dos outros, bem como do objeto da fala.

A este processo vincula-se uma formação discursiva. De acordo com Maingueneau (1997), formação discursiva é entendida a partir das ideias de Foucault como: "Um conjunto de regras anônimas, históricas, sempre determinadas no tempo e no espaço que definiram em uma época dada, e para uma área social, econômica, geográfica ou linguística dada, as condições de exercício da função enunciativa" (FOUCAULT, 1969 apud MAINGUENEAU, 1997, p.14).

Brandão (2004, p. 106) afirma que a formação discursiva pode ser compreendida como um "conjunto de enunciados marcados pelas mesmas regularidades, pelas mesmas regras de formação", definindo-se pela sua relação com uma formação ideológica, de modo que "os textos que fazem parte de uma formação discursiva remetem a uma mesma formação ideológica". Para Haroche et al. (1971 apud ORLANDI, 2009, p. 27): "Cada formação ideológica constitui um conjunto complexo de atitudes e representações que não são nem individuais nem universais, mas se reportam mais ou menos diretamente às posições de classe em conflito umas com as outras".

Assim, todo dizer se filia, mesmo que inconscientemente, a certa formação discursiva, que, por sua vez, está relacionada a uma formação ideológica, estabelecendo o que pode e deve ser dito a partir de um lugar historicamente determinado: “as formações discursivas são componentes das formações ideológicas e determinam o que pode e deve ser dito a partir de uma posição dada em uma conjuntura dada" (ORLANDI, 2009, p. 27).

Esta concepção de linguagem permite uma compreensão fundamental sobre o fenômeno da interpretação, inerente às diversas esferas de atuação humana, dentre as quais a educação escolar, podendo justificar a ocorrência das fases de desenvolvimento curricular sugeridas por Gimeno Sacristán, não somente por razões imediatas associadas à dinâmica dos sistemas escolares, mas também pela intrínseca e inevitável relação entre sujeitos, mundo e linguagem no processo interpretativo de atribuição de sentidos. Representantes oficiais do Estado, formuladores de propostas curriculares, elaboradores de materiais didáticos, gestores escolares, professores e estudantes se situam em posições específicas e estão inseridos em formações ideológicas e 
discursivas que, embora compartilhem certas características do discurso pedagógico, apresentam nuances particulares que conduzirão à produção de diferentes significados sobre o currículo e outros aspectos do mundo escolar.

Orlandi (2009) destaca que uma característica essencial associada ao discurso pedagógico é seu caráter autoritário, de não neutralidade, que se dissimula como mero transmissor de informação, recoberto pela rubrica da cientificidade e institucionalmente legitimado. Por ser um discurso institucional, o discurso pedagógico "reflete as relações institucionais das quais faz parte” (ORLANDI, 2009, p. 37) e, se tais relações são autoritárias, ele será autoritário, ainda que críticas sejam possíveis. Em nosso entender, mesmo havendo movimentos em outras direções, as ações referentes à educação formal se praticam ainda como um processo de inculcação nas relações entre os diversos níveis da estrutura hierarquizada do sistema educativo.

Respaldados em Bourdieu (1974), podemos pensar a escola como lugar de reprodução cultural e das estruturas das relações sociais, de poder e econômicas, mascarada por uma aparente neutralidade. Segundo Orlandi (2009, p. 23), isso se dá porque:

A escola atua através da convenção: o costume que, dentro de um grupo, se considera como válido e está garantido pela reprovação da conduta discordante. Atua através dos regulamentos, do sentimento de dever que preside ao discurso pedagógico e este veicula. Define-se como ordem legítima porque se orienta por máximas que aparecem como válidas para a ação, isto é, como modelos de conduta, logo, como obrigatórias. Aparece, pois, como algo que deve ser. Na medida em que a convenção, pela qual a escola atua, aparece como modelo, como obrigatória, tem o prestígio da legitimidade.

No que se refere às relações políticas envolvidas na construção do discurso pedagógico oficial, professores e estudantes encontram-se, em geral, excluídos das decisões pronunciadas pelos que detêm uma posição de poder sobre a educação quanto à definição de seus conteúdos, sua forma e finalidades. Por outro lado, são os protagonistas quando se trata do trabalho em sala de aula, com suas atitudes em relação às prescrições que lhes são feitas sendo as mais variadas, tendo, como casos extremos, a resistência e a subserviência, por vezes, acríticas e não reflexivas.

Uma forma de desenvolver uma posição crítica em relação ao discurso pedagógico assim caracterizado é tentar torná-lo um discurso polêmico no sentido da AD francesa. Tratase, sobre o discurso educacional,

[...] de atuarmos criticamente nas duas direções, em relação aos que nos cristalizam (os que se pronunciam sobre a educação) e ao que nós, reprodutoramente, cristalizamos em nosso trabalho de educação. [...] de um lado, deve-se questionar os implícitos, os locutores, a finalidade e o sentido dado ao ensino pelo discurso pedagógico do poder e, de outro, fazer o mesmo com o discurso que nós reproduzimos internamente no trabalho pedagógico. (ORLANDI, 2009, p. 35, grifos do autor)

Quando na posição de autores, que os participantes do processo educativo construam seus discursos expondo-se a efeitos de sentidos possíveis, "deixando espaço para a existência do 
outro (o ouvinte) como sujeito" (ORLANDI, 2009, p. 32), isto é, que saibam colocar-se como ouvintes do próprio do discurso e do outro. Quando na posição de ouvintes, que exerçam sua capacidade de discordância, recusando a rigidez do que é dito e a estagnação permanente em um papel passivo. Tal dinâmica viabilizaria uma reflexão efetiva sobre os objetos de estudo, podendo contribuir para superar o caráter estritamente cognitivo e informacional do discurso pedagógico autoritário tradicional.

Com base nestas noções sobre o funcionamento da linguagem e o discurso pedagógico, apresentamos, a seguir, os aspectos metodológicos e as análises que compõem os resultados desta pesquisa.

\section{Aspectos metodológicos}

O curso "Práticas de Ensino de Física e o Currículo do Estado de São Paulo - módulo I" foi desenvolvido no segundo semestre do ano de 2013, por meio de uma colaboração entre a Diretoria de Ensino da Região de Santo André - SP e uma Universidade Federal situada no Estado de São Paulo. A concepção e o planejamento do curso se deram a partir do contato dessa Diretoria com a Universidade, com o intuito de propiciar uma formação continuada a professores que lecionam Física nas escolas públicas da região. O conteúdo do curso correspondeu aos temas previstos no currículo oficial do Estado para o $3^{\circ}$ e $4^{\circ}$ bimestres de cada uma das três séries do Ensino Médio, a saber: Universo, Terra e Vida para o primeiro ano; Som, imagem e comunicação para o segundo ano; Matéria e Radiação para o terceiro ano. Sua duração foi de 30h, sendo $24 \mathrm{~h}$ presenciais, com encontros aos sábados pela manhã em uma sala de aula na sede da Diretoria de Ensino. A inscrição dos professores das escolas públicas no curso foi voluntária e realizada pelo Núcleo Pedagógico da Diretoria, totalizando 23 inscrições.

De modo geral, pode-se afirmar que a finalidade da formação continuada é o aperfeiçoamento teórico e prático do professor, necessário para seu desenvolvimento profissional. Segundo Gatti (2000), tais ações formativas, realizadas no próprio ambiente de trabalho do professor ou fora dele, deveriam contemplar situações que envolvam interações com trocas de informações, experiências e reflexões entre os participantes. Ferreira (2008) enfatiza que a formação continuada não deveria ser restrita a mera acumulação de cursos com caráter estritamente técnicos, mas como uma oportunidade para a promoção de uma reflexão crítica sobre a prática, o que contribuiria para a formação de um professor efetivamente reflexivo e responsável por seu próprio desenvolvimento profissional, como preconiza Nóvoa (1992). No planejamento e desenvolvimento do curso, procurou-se valorizar a interação entre todos os envolvidos e os heterogêneos saberes dos professores, construídos no exercício de suas funções e originados de suas experiências pessoais, constituindo o que Tardif e Lessard (2011) denominam "saberes experienciais". Com relação ao professor: “[...] os saberes para a docência são uma realidade social materializada através de uma formação, de programas, de práticas coletivas, de disciplinas escolares, de uma pedagogia institucionalizada, etc., e são também, ao mesmo tempo, saberes dele" (TARDIF; LESSARD, 2011, p. 16).

A metodologia utilizada no desenvolvimento do curso visando à incorporação destes princípios e a análise da produção dos professores referente aos conteúdos estudados pode ser encontrada em Watanabe-Caramello, Zanotello e Pires (2014). 
A produção dos professores, referente à presente pesquisa de natureza qualitativa e empírica (BOGDAN; BIKLEN, 1994), foi registrada a partir de suas respostas por escrito a questões propostas no início e no final do curso. No primeiro encontro, após a apresentação geral do curso, os professores foram convidados a responder individualmente o questionário transcrito no Quadro 2.

Quadro 2. Questionário inicial aplicado aos professores participantes do curso de formação continuada

1) Qual sua formação na graduação?

2) Em qual instituição e em que ano se graduou?

3) Há quanto tempo leciona Física na rede pública?

4) Em quais séries leciona atualmente?

5) Quais suas expectativas em relação a este curso?

6) Considerando o currículo oficial do Estado de São Paulo, em sua opinião, quais são seus aspectos positivos e negativos?

7) Com relação às situações de aprendizagem propostas nos cadernos do professor e do aluno, você sente dificuldades em desenvolvê-las nas aulas? Em caso afirmativo, pontue suas principais dificuldades.

8) Além dos cadernos oficiais, você costuma utilizar outros recursos (como livros didáticos, paradidáticos, documentários, revistas, jornais, atividades experimentais, recursos computacionais etc.) em suas aulas?

9) No que se refere a atividades experimentais, você costuma realizá-las em aula? Justifique. Em caso afirmativo, dê exemplos de atividades dessa natureza que você já realizou.

10) Com relação aos conteúdos e conceitos de Física Moderna e Contemporânea constantes nos cadernos, quais deles você considera mais difíceis e complicados de serem tratados nas aulas? Justifique.

Fonte: elaborado pelos autores.

No último encontro, os professores expressaram posicionamentos sobre o curso e suas considerações sobre o currículo após as vivências e discussões nos encontros, respondendo à seguinte solicitação:

Escreva suas impressões sobre o curso e como você considera, após a realização do curso, o currículo oficial do Estado de São Paulo para a disciplina de Física.

Todas as questões foram respondidas sem que os professores se identificassem, preservando o anonimato dos mesmos. A partir da análise desse material, evidenciamos certos sentidos que os professores atribuem ao currículo e que influenciam suas práticas, tendo o curso de formação como uma das condições de produção destes sentidos. E, a fim de compreendermos aspectos do discurso pedagógico veiculado pelos documentos oficiais que constituem o currículo prescrito, procedemos, também, a uma leitura dos mesmos. 


\section{Análises}

\section{a) Documentos curriculares oficiais}

A Secretaria da Educação do Estado de São Paulo propôs, em 2008, um currículo básico para suas escolas, nos níveis de Ensino Fundamental (ciclo II) e Ensino Médio (EM), cujo corpus consiste de três conjuntos de documentos. O primeiro conjunto é constituído por cadernos nos quais são apresentados os princípios fundadores e a estrutura do currículo para cada área, como no caso das Ciências da Natureza e suas Tecnologias (SÃO PAULO, 2010). O segundo conjunto é composto pelos cadernos do professor e do aluno. Tais cadernos são organizados por disciplinas, séries e bimestres, divididos por blocos temáticos. Os temas são trabalhados a partir de "situações de aprendizagem", denominação esta utilizada nos próprios cadernos, nas quais há a proposição de métodos, recursos e estratégias, tais como: experimentação, projetos coletivos e atividades extraclasse. Em cada situação de aprendizagem, são explicitados: o número de aulas destinadas ao seu cumprimento, os conteúdos específicos abordados, as competências e habilidades envolvidas, bem como itens para avaliação. O terceiro conjunto de documentos, com orientações para a gestão do currículo na escola, é denominado caderno do gestor, e dirige-se, sobretudo, aos diretores das escolas, aos professores coordenadores e supervisores.

No início do caderno que contém os textos básicos do currículo do Estado de São Paulo para as Ciências da Natureza e suas Tecnologias (SÃO PAULO, 2010), há uma carta do então Secretário da Educação aos professores e gestores, na qual afirma que estes documentos:

[...] são as referências essenciais para o estabelecimento das matrizes de avaliação do Sistema de Avaliação de Rendimento Escolar do Estado de São Paulo (Saresp), dos programas de reforço e recuperação e dos cursos de formação continuada de nossa Escola de Formação de Professores. (SÃO PAULO, 2010, p. 3)

Este trecho evidencia que, apesar de um tom propositivo adotado em certas partes dos documentos, o Estado espera que seu currículo seja efetivamente seguido, e indica mecanismos de avaliação nele pautados que induzem sua adoção pelas comunidades escolares.

Na sequência, a coordenadora geral do projeto "São Paulo faz escola", a partir do qual se gerou o currículo oficial, coloca que o currículo "é hoje uma realidade nas escolas públicas paulistas graças ao empenho de todos os seus profissionais" (SÃO PAULO, 2010, p. 4). A referência à participação de todos, que se repete em outro trecho da mesma apresentação, pode ser vista como uma tentativa de legitimar o documento, procurando fazer com que todos se apropriem das diretrizes nele estabelecidas por se sentirem coparticipantes de sua construção.

Um princípio fundador no projeto é o da uniformização, expresso na expectativa de que todos os estudantes de todas as escolas tenham iguais oportunidades de acesso aos mesmos conhecimentos atualizados e significativos valorizados pela sociedade, pela realização do mesmo percurso de aprendizagem nas disciplinas básicas. Em todas as disciplinas, estão descritos: os conteúdos, as competências e habilidades, as estratégias metodológicas e o que se espera dos alunos em cada série e bimestres. Este nível de organização chega ao do "aula a aula". 
$\mathrm{Na}$ medida em que o Secretário afirma que os cadernos serão referências para processos de avaliação e formação de estudantes, professores e gestores das escolas, com reflexos inclusive em suas remunerações, e é apresentado, aos membros das comunidades escolares, um minucioso detalhamento de como desenvolver as componentes curriculares, nos parece que estes discursos contribuem para inibir professores e gestores a desenvolverem ações autônomas. Ainda em sua apresentação, a coordenadora geral do projeto escreve que, no espaço escolar, "mesmo que as diferenças sejam consideráveis, os profissionais devem ter clareza sobre os propósitos comuns da educação, para que se organizem em função desses propósitos" (SÃO PAULO, 2010, p. 4). E acrescenta que:

Neste documento, são apresentados conteúdos que versam sobre currículo, planejamento e avaliação de forma a subsidiar o professor e o gestor em suas práticas para implementar o Currículo do Estado de São Paulo, organizar sua crítica e construir a Proposta Pedagógica que representa sua identidade escolar. (SÃO PAULO, 2010, p. 4)

$\mathrm{Na}$ perspectiva discursiva adotada, estes propósitos comuns da Educação não existem de forma absoluta, sendo construídos historicamente em determinados contextos sociais, políticos e econômicos, materializando-se no que Gimeno Sacristán (2000) considera como currículo prescrito, nesse caso, pelos representantes do Estado que elaboraram os documentos. E, qualquer que seja a identidade da escola em particular, sua proposta pedagógica deve abarcar a implementação do currículo oficial. Apesar de falar em autonomia das escolas, o Estado espera e cria mecanismos para que seu currículo seja cumprido, sob a égide de que isso melhorará a qualidade da educação escolar oferecida.

Como um destes mecanismos, o caderno do gestor:

Tem a finalidade específica de apoiar o gestor para que ele seja um líder capaz de estimular e orientar a implementação do Currículo nas escolas públicas estaduais de São Paulo. [...] as propostas pedagógicas que devem organizar o trabalho nas condições singulares de cada escola têm por função assegurar aos alunos a aprendizagem dos conteúdos e competências previstas no currículo. (SÃO PAULO, 2010, p. 8)

Com relação aos cadernos do aluno e do professor, que se configuram no que Gimeno Sacristán (2000) chama de currículo apresentado ao professor, o documento diz que: "A utilização dos cadernos, concebidos de forma coerente com essas diretrizes curriculares, são compatíveis com o uso de diferentes manuais e livros didáticos, assim como de paradidáticos e vídeos" (SÃO PAULO, 2010, p. 30).

Ao se compararem os conteúdos dos cadernos com os constantes em livros didáticos usuais de Física para o Ensino Médio, esta suposta compatibilidade não parece ser tão óbvia em virtude das diferenças que estes materiais possuem, tanto na organização dos assuntos para cada série como no grande número de atividades que a utilização conjunta destes materiais acarretaria em comparação com a diminuta quantidade semanal de aulas na maioria das escolas da rede. 
No currículo de Física, os conteúdos estão distribuídos em seis grandes temas: Movimentos - grandezas, variações e conservacõos; Universo, Terra e vida são os dois temas para o $1^{\circ}$ ano do EM. Calor, ambiente e usos da energia; Som, imagem e comunicação são os temas do $2^{\circ}$ ano. Equipamentos elétricos; Matéria e radiação são os temas para o $3^{\circ}$ ano. Esta organização curricular tenta se aproximar de algumas diretrizes gerais para o ensino escolar da Física estabelecidas em documentos como os Parâmetros Curriculares Nacionais (PCN) (BRASIL, 2000), PCN+ (BRASIL, 2002) e das Orientações Curriculares para o Ensino Médio (BRASIL, 2006), tais como: as que preconizam a valorização da interdisciplinaridade, o entendimento dos modos de produção do conhecimento científico e suas implicações sociais, os aspectos culturais e aqueles relacionados ao cotidiano dos alunos, e a incorporação de conteúdos de Física Moderna e Contemporânea, ainda que algumas delas não pareçam devidamente contempladas nos cadernos.

Em nossa leitura dos documentos oficiais, a proposta curricular do Estado de São Paulo vai além de meras sugestões de um currículo mínimo, pois consiste em uma complexa proposta que contém: orientações axiológicas, determinações metodológicas, especificação de conteúdos para todas as áreas e critérios de avaliação. As exigências presentes no currículo prescrito têm por efeito influenciar de forma direta a prática de professores e estudantes nas aulas. Os cadernos do professor e dos estudantes, entendidos como manuais didáticos que materializam o currículo apresentado aos membros da comunidade escolar, são meios que visam padronizar conteúdos e atividades trabalhados nas aulas.

\section{b) Discursos dos professores sobre o currículo oficial}

Dos 23 professores participantes do curso, quatro eram formados em Física, cinco em Química e 14 em Matemática. Estes números refletem uma situação preocupante do ponto de vista do ensino de Física nas escolas públicas que acreditamos ser geral, não se restringindo à região em que o curso foi ministrado: a carência de professores de Física com formação na área. Quanto ao tempo de magistério na rede pública, o perfil era bastante heterogêneo. $\mathrm{O}$ professor que estava há mais tempo em atividade possuía, na ocasião, 18 anos de docência, e havia um professor que estava no terceiro ano da graduação em licenciatura em Matemática. Este lecionava Matemática e Ciências no Ensino Fundamental II, mas, como pretendia futuramente lecionar Física, interessou-se pelo curso de formação. Além da atuação nas três séries do Ensino Médio regular, dois professores trabalhavam com Física também na Educação de Jovens e Adultos (EJA).

As expectativas apontadas pelos professores com relação ao curso foram variadas. O aprendizado de certos conteúdos de Física - trabalhar com a experimentação, articular o currículo com os livros didáticos, desenvolver aulas mais dinâmicas para atrair a atenção dos seus alunos e buscar subsídios para o trabalho na EJA - estava entre os objetivos manifestos pelos docentes, conforme ilustram os trechos seguintes. A fim de preservar o anonimato, os professores são identificados pelos códigos P1, P2,..., P23.

Adquirir mais conhecimentos e aprender mais experimentos para usar nas aulas. [P1] Discutir as experiências propostas nos cadernos: algumas pouco explicativas, não indicando como desenvolver os equipamentos [...] faltam materiais para realizar os experimentos. [P3] 
Tornar a linguagem mais acessivel aos alunos. [P5]

Não tenho conhecimentos sobre diversos conteúdos, pois não os tive na graduação. Espero aprender mais e ter nova visualização da matéria. [P7]

Aprimorar conceitos, alinhar o curriculo do estado aos livros didáticos, motivar o aluno. [P8]

Trabalhar compreensão e dinamismo nas aulas, obtendo atenção e interesse dos alunos. [P13]

Buscar mais informações para adaptar ao EJA. [P15]

Apesar da diversidade de expectativas, foi recorrente a de conseguir realizar experimentos, indicando que, no imaginário desses professores, há uma tendência a considerar práticas de laboratório e experimentação como alternativas para melhorar o ensino e a aprendizagem nas aulas de Física. Este papel atribuído à experimentação, por vezes supervalorizado, insere-se em uma formação ideológica compartilhada pelos professores que é característica dos discursos já produzidos sobre o ensino de Física e veiculados ao longo do tempo em projetos de ensino, materiais didáticos e documentos oficiais.

A partir dos dizeres de P5, P8 e P13, evidencia-se uma busca pelo aluno. Os professores anseiam conseguir maior envolvimento, atenção e participação dos estudantes, procurando uma linguagem acessível a eles por meio de práticas mais dinâmicas. O desafio de tornar as aulas estimulantes e que os processos de ensino e aprendizagem possam ser mais interessantes e prazerosos é um problema caro aos professores que requer um enfrentamento conjunto a partir das suas condições reais e peculiares de exercício da docência, cabendo às iniciativas de formação continuada promover o diálogo necessário em torno dessas questões.

Algumas leituras dos professores sobre o currículo oficial, registradas nas respostas dadas à questão 6, são apresentadas no Quadro 3.

A unificação dos conteúdos pela divisão dos mesmos em séries e bimestres possui certos aspectos positivos, como indicam $\mathrm{P} 3$ e $\mathrm{P} 6$, no que se refere à mobilidade de estudantes entre as escolas durante o ano letivo e a uma eventual discrepância considerável entre os assuntos abordados por diferentes professores de uma mesma disciplina em determinada série. O fato de conter experimentos, temas novos como "Universo" e procurar contextualizar, de algum modo, os conteúdos, também são aspectos destacados, a princípio, como positivos. Com relação aos problemas, cabe destacar a preocupação de P15 com a modalidade EJA, que parece não receber a devida atenção, ficando seus professores sem referências adequadas. Sobre a ênfase dada nos materiais oficiais ao desenvolvimento de competências e habilidades, há os que consideram isto fundamental, como $\mathrm{P} 4$, e os que adotam um posicionamento enfocando sua prática nos conteúdos, como P3. Isto revela que tentar estabelecer uma matriz equilibrada entre competências/habilidades e conteúdos é uma tarefa desafiadora e não trivial. 
Quadro 3. Aspectos positivos e negativos sobre o currículo oficial destacados pelos professores no início do curso

\begin{tabular}{|c|c|}
\hline Aspectos positivos & Aspectos negativos \\
\hline $\begin{array}{l}\text { Não é de toda ruim, ela precisa ser adequada } \\
\text { aos conteúdos com o livro didático. [P1] } \\
\text { Unifica o currículo, diminuindo transtornos } \\
\text { quando chega um aluno de outra escola; } \\
\text { enfatiza conceitos e algumas correlações com a } \\
\text { realidade. [P3] } \\
\text { Enfatizar competências e babilidades. [P4] } \\
\text { Enfatizar os experimentos. [P5, P7, P13, } \\
\text { P17] } \\
\text { Uniformiza um pouco mais o que é ensinado, } \\
\text { já que os conteúdos eram ministrados a gosto } \\
\text { dos professores e da escola. [P6] } \\
\text { Gosto da inserção do tema "Universo". [P8] } \\
\text { O mesmo conhecimento para todos; material } \\
\text { igual para todos e algumas experiências } \\
\text { interessantes. [P9, P11] } \\
\text { Ter o caderno do aluno. [P12] } \\
\text { Contextualização do conteúdo. [P16, P17, } \\
\text { P18] } \\
\text { Abordagem por temas. [P19] } \\
\text { Procura mostrar as relevâncias do ensino da } \\
\text { fisica. [P20] } \\
\text { Amplo e diversificado. [P23] }\end{array}$ & $\begin{array}{l}\text { Os experimentos, que muitas vezes não conseguimos desenvolver } \\
\text { devido à falta de material e laboratório de física nas escolas. [P1, } \\
\text { P7] } \\
\text { Mecânica fica comprimida em } 2 \text { bimestres no } 1^{\circ} \text { ano, não dá para } \\
\text { tratar adequadamente e pouco tempo para exercícios. Sistema solar } \\
\text { e espaço fica com } 2 \text { bimestres, é muito tempo para isso; há minúcias } \\
\text { que os alunos não se interessam. Eletricidade também fica com } \\
\text { pouco tempo. Física moderna tem minúcias demais. [P3] } \\
\text { Tempo restrito para abordagem e fixação dos conceitos e } \\
\text { desenvolvimento dos temas. [P2, P4, P5] } \\
\text { Não há laboratório adequado para as experiências; algumas têm } \\
\text { que fazer previamente e muitas vezes me falta tempo; muito do que é } \\
\text { exposto exige pré-requisitos que os alunos não têm. [P6] } \\
\text { Falta de material para as práticas. [P9, P19, P20] } \\
\text { Fora da realidade; professores e alunos têm muitas dificuldades em } \\
\text { entender. [P10, P17, P16] } \\
\text { Falta conteúdo teórico nas apostilas, alguns assuntos complicados } \\
\text { demais para o aluno. [P11] } \\
\text { Temas muito abrangentes. [P12] } \\
\text { Não dá para usar no EJA. [P15] } \\
\text { Alunos apresentam muita dificuldade nas interpretaçoees de texto e } \\
\text { exercícios. Falta de tempo para preparar as aulas. [P16, P18] } \\
\text { Com apenas } 2 \text { aulas por semana é difícil cumprir com a qualidade } \\
\text { devida. [P23] }\end{array}$ \\
\hline
\end{tabular}

Fonte: elaborado pelos autores.

A reorganização dos temas nos cadernos é tida como problemática por P3. Nos casos de Mecânica e Eletromagnetismo, se tratam de temas tradicionalmente extensos, desenvolvidos por mais tempo e com maior detalhamento nos livros didáticos em comparação com os cadernos. Para este professor, isto é um conflito entre o que ele considera um ensino adequado e o que lhe é colocado pelo currículo. Seu dizer remete a uma formação discursiva característica de um imaginário sobre o que deve ser o ensino de Física, veiculado, por exemplo, pelos livros didáticos. Tanto os livros que são destinados ao Ensino Médio quanto aos anos iniciais do Ensino Superior apresentam, essencialmente, os mesmos conteúdos e subdivisões em tópicos. Neste aspecto, os cadernos propõem mudanças em relação a um enfoque historicamente legitimado 
para o ensino de Física, construindo uma crítica pertinente e fomentando discursos polêmicos em torno da questão que devem ser ponderados.

Quando P10, P17 e P16 colocam que "professores e alunos têm muitas dificuldades em entender"o currículo oficial, evidencia-se a não-transparência da linguagem. O que pode parecer absolutamente claro para determinados sujeitos em certas posições, é interpretado de modo diferente por outros sujeitos em diferentes posições. Esta ilusão do sentido "já lá”, como um dado a ser decodificado, é um efeito ideológico no funcionamento da linguagem que a AD procura elucidar. Ao curso de formação caberia explicitar variados aspectos ideológicos e discursivos em jogo a respeito do ensino da Física, criando condições para que os professores atribuam novos sentidos à sua prática. No curso que desenvolvemos com este grupo de professores, tais condições envolveram: leituras críticas do currículo prescrito e apresentado, a consideração de seus saberes experienciais, o estudo de certos conteúdos por eles demandados, e a proposição e discussão de metodologias de ensino e recursos didáticos alternativos, sempre à luz das reais condições de trabalho dos docentes.

Sobre as situações de aprendizagem constantes nos cadernos do professor e do aluno, certas dificuldades foram explicitadas.

No caderno existem muitas situacões óbvias que irritam os alunos, atividades introdutórias e de sensibilização. Faltam exercícios. Física moderna não tem textos em todos os tópicos e os livros didáticos não contemplam certos assuntos. [P3]

Muito conteúdo para pouco tempo. [P4]

Não tenho conbecimento suficiente para realizar alguns dos experimentos propostos. [P7]

Falta de recursos materiais e tempo para preparar o laboratório. [P11]

Os alunos não gostam do material, não trazem, perdem, jogam fora... [P12]

Não trabalho o caderno em si, só os conteúdos. [P14]

O único caderno possivel de utilizar no EJA é o de eletricidade. Gosto da atividade sobre consumo de energia com base na conta de luz de cada um. [P15]

Muitas vezes o conteído do caderno não bate com os livros didáticos. [P19]

Gosto dos assuntos e pesquiso para atender a proposta. [P20]

Os professores foram unânimes ao afirmarem que utilizam, sistematicamente, livros didáticos, mas que encontram dificuldades em articulá-los com os cadernos oficiais. Enquanto P14 admite não trabalhar os cadernos, P20 afirma gostar da proposta e pesquisar para atendê-la. Estas distintas atitudes ilustram ações modeladoras que os professores exercem sobre o currículo. E tais ações se fundamentam em seus imaginários sobre como deve trabalhar um professor de Física. Poucos professores recorrem a outros recursos como leituras, trechos de filmes ou sites na internet. Mesmo as atividades experimentais, bastante incentivadas e difundidas ao longo do 
material oficial, não são realizadas com frequência, devido, segundo eles: à pequena quantidade de aulas de Física semanais, à falta de materiais e espaços adequados na maioria das escolas, e à falta de tempo para preparar as atividades, decorrente do grande número de aulas semanais que costumam assumir.

Utilizo livros didáticos, mas o cronograma dos livros não segue o dos cadernos. A parte de planetas e galáxias não é esmiuçada nos livros, então faltam subsídios teóricos para as aulas com o caderno. O mesmo com física moderna, e os alunos não pesquisam nada. [P3]

Livros didáticos, alguns trechos de filme e experimentos. [P4]

Livros didáticos para fazer um resumo, um apanhado geral para os alunos. [P6]

Recursos computacionais: meus alunos não têm interesse em estudar, porém gostam de ficar conectados a redes sociais, etc. Assim, peço pesquisas e trabalhos e tento utilizá-los em aula. [P7]

Uso outras fontes (livro didático) por sentirfalta de confiança nos cadernos oficiais. [P10]

Especificamente em relação às atividades experimentais, os motivos alegados para a não-realização das mesmas recaem na falta de tempo, espaço físico e material nas escolas. Além destes, consideramos que o fato de a maioria dos professores em exercício não ter formação em Física também pode ser um motivo, uma vez que cursos de graduação em outras áreas não propiciam, em geral, práticas efetivas em laboratórios de Física voltados para a formação do professor na Educação Básica. Isto deve gerar receios e inseguranças nos professores que assumem aulas de Física e se veem impelidos à realização de tais práticas. Dentre os que afirmaram realizar experimentos em suas aulas, foi revelado que tais iniciativas são pontuais e apresentam um caráter predominantemente ilustrativo, com o professor realizando demonstrações para os estudantes, o que se justifica em vista das dificuldades apontadas por eles para este tipo de prática.

Não bá muito tempo para fažer, mas algumas já realizei: calorímetros improvisados, condução de convecção de calor, óptica, mistura de cores com tinta, espelhos, decomposição da luz e disco de Newton, eletricidade... tipos de lâmpadas, circuitos em série e em paralelo. [P3]

No $3^{\circ}$ ano trouxe imãs e o filme "O núcleo - viagem ao centro da Terra". [P5]

No $3^{\circ}$ ano monto circuitos em série e em paralelo para observar alguns efeitos como apagar de algumas lâmpadas, calcular corrente e resistência. No $2^{\circ}$ ano faço uma demonstração com o gelo até a ebulição para faz̧er um gráfico. [P6]

Conversão energia mecânica em elétrica, molas e constante elástica, construção de uma balança, termômetro a álcool, circuitos em série e em paralelo, câmara escura, altofalante. [P8] 
Experimentos de velocidade no pátio com bolas e cronômetros, montagem de circuitos elétricos e instrumentos musicais. [P11]

Notamos que dificuldades pela não-formação em Física são mais flagrantes na abordagem de temas relacionados à Física Moderna e Contemporânea (FMC) nos cadernos do $3^{\circ}$ ano. Todos os professores colocaram que não conheciam diversos dos assuntos neste tema do currículo. Nos encontros em que foram analisados os cadernos do $3^{\circ}$ e $4^{\circ}$ bimestres do $3^{\circ}$ ano, procuramos trabalhar determinados conteúdos e conceitos, como os efeitos relativísticos da dilatação do tempo e da contração do espaço, bem como o modelo de Bohr para o átomo de hidrogênio, com o intuito de fornecer subsídios a este grupo de docentes. Sobre aspectos da FMC, seguem alguns comentários dos professores.

Relatividade: dificil explicar dilatação do tempo, paradoxo dos gêmeos é um assunto que os alunos não acreditam. Particulas elementares: existem muitas e não fica claro para que servem. Microeletrônica: o tema atrai, mas não tem material teórico adequado nos livros e no caderno. Os alunos não se motivam em pesquisas na internet. [P3]

Todos os temas de física moderna são dificicis: falta de formação, aplicaşão e abordagem no dia a dia. [P4]

Só vejo sentido em Astronomia e Cosmologia. [P8]

A maioria dos alunos não tem interesse nesses temas, o que pode tornar a aula chata. [P10]

Dificil os alunos compreenderem a parte física do modelo de Bohr. [P12]

Isto evidencia que a inserção efetiva da FMC no Ensino Médio não se dará apenas por prescrições curriculares, mas carece de um trabalho junto aos docentes que mescle a formação conceitual e as possibilidades metodológicas e estratégicas para a prática desses conteúdos.

Os relatos dos docentes revelam ações modeladoras que eles exercem sobre o currículo apresentado, ações estas que se materializam em práticas efetivamente realizadas em sala de aula conforme o modelo de Gimeno Sacristán, configurando-se como resultado de um processo interpretativo no qual estão em jogo relações entre linguagem e mundo na constituição dos sujeitos e suas vinculações a formações discursivas e ideológicas constitutivas do discurso pedagógico relacionado ao ensino de Física.

\section{a) Posicionamentos dos professores ao final do curso}

No último encontro, os professores destacaram aspectos que consideraram positivos e os momentos que lhes pareceram mais significativos, registrando suas impressões por escrito. Consideramos que foi possível desenvolver o curso de maneira colaborativa, dando oportunidade aos professores interagirem e expressarem suas dúvidas, inseguranças e desafios encontrados no dia a dia, utilizando-os como subsídios para preparação dos encontros. A maioria dos par- 
ticipantes sugeriu que a duração do curso fosse maior e que outras iniciativas dessa natureza seriam úteis. Seguem alguns de seus comentários.

Foi muito bom referente aos conteúdos, sugestões de pesquisa e contextualização. Tenho que aprimorar e adaptar para aplicar com meus alunos. [P1]

Deu uma visão geral dos assuntos em foco e preencheu as lacunas de alguns professores na área. Seria bom mais aplicações práticas e um material escrito em apostila para aprofundar nosso conbecimento. [P2]

Foi um ótimo momento para trocas de experiências e vivências e para adquirir conhecimentos. [P3]

O momento mais proveitoso foram os vídeos que demonstram melhor os assuntos. [P4]

A linguagem foi adequada, trazendo tranquilidade e segurança. Recomendaria um tempo maior para tratar os temas. [P5]

Deu uma visão melhor do caderno do aluno, facilitando os métodos de utilização do próprio. [P7]

Foi de suma importância para o esclarecimento do conteúdo de Física Moderna. O não conbecimento do conteúdo faz com que tenhamos uma falta de tempo e interesse para estudar e se aprofundar nos assuntos. [P9]

Mudou a minha maneira em particular de começar minhas aulas. [P14]

Poderíamos montar um curso sobre experimentos propostos na apostila e modificando para melhorar os resultados. [P15]

Iniciativa de formação de um modo mais tecnológico através de vídeos, programas, mídias, foi importante, pois é isso que o aluno quer hoje e convenhamos não pode ser diferente. Os encaminhamentos de experiências foram muito bons. Sugiro outros cursos de formação para melhorar a condição do professor no que se refere à disciplina que ministra. O que falta e muito é preparo para o professor. [P17]

Tornou possivel realizar as experiências, quebron o muro da impossibilidade. [P19]

Além das impressões sobre o curso, perguntamos como eles passaram a ver o currículo oficial, no intuito de identificarmos possíveis novas concepções que tenham se formado. Mesmo conscientes de que as supostas contribuições do curso podem ter um efeito transiente, não duradouro e que talvez não se reflitam efetivamente no trabalho cotidiano destes professores, a maioria indicou que ao menos alguns aspectos foram ponderados e objetos de reflexão. Em particular, P3 reafirma a natureza política do currículo, ao passo que P5 e P6 criticam a falta 
de atualização dos cadernos.

Algumas situações de aprendizagem serão possiveis de aplicar. [P1]

Seria bom que alguns textos fossem adicionados ao caderno do aluno para facilitar o ensino de quântica e relatividade, que são de difícil aplicaşão. [P2]

A proposta continua sendo política, porém agora com um norte para programação e preparação dos conceitos. [P3]

Sempre fui a favor da proposta curricular e só fortaleceu meus argumentos. Não sou a favor do caderno do aluno da forma como está sendo produzido e distribuido. Há resposta das questões na internet. [P5]

Dá para aproveitar muita coisa dos cadernos, mas poderia ser mais aproveitado com a melhoria do mesmo. [P6]

Ficou melhor interpretada facilitando o seu uso. [P7]

Maior clareza na proposta, porém só utilizo como apoio. [P8]

Reformulei totalmente a minha maneira de usar os cadernos. Não colocando o conteúdo mastigadinho, mas levando os alunos a pensar, visando competências e babilidades dos mesmos. [P14]

Os momentos da experiência fazem diferença para a aprendizagem. Aprimora fazer a relação teoria $\times$ prática. [P16]

Com certeza bouve mudanças principalmente nos preparos das aulas utilizando os três momentos. Percebemos resultados diferentes dos que estávamos acostumados a receber dos alunos, resultados com maior compreensão. [P18]

Deveria ter mais aulas de física no EM para poder passar todas essas informações aprendidas aos nossos alunos. [P20]

Procuramos trabalhar as situações de aprendizagem de maneira crítica ao longo do curso, propondo alternativas aos experimentos que apresentavam maiores dificuldades de realização na sala de aula e a outras atividades constantes nos cadernos. Apresentamos, discutimos e aplicamos, com os professores, a metodologia dos três momentos pedagógicos (DELIZOICOV; ANGOTTI, 1988) como subsídio à contextualização dos assuntos, estimulando a reflexão sobre a prática e acolhendo suas dificuldades. Pelos relatos expressos, esta maneira de conduzir o curso se revelou adequada a este grupo de professores, tendo, para P18, um significado efetivo que já começa a refletir em sua atuação. Por outro lado, P8 afirma que, apesar de ter maior clareza sobre a proposta curricular, continua seguindo um modelo tradicional que lhe faz mais sentido. 
Levantamos as principais questões dos professores em relação a cada situação de aprendizagem, e discutimos, em conjunto, possíveis soluções. Por exemplo, no estudo das leis de Kepler, além de fazer a atividade de traçado da elipse sugerida no caderno, os professores questionaram sobre como contextualizar esse assunto com os estudantes, mostrando a relevância e as possíveis aplicações atuais deste conhecimento. No experimento proposto para ilustrar a reflexão da luz em espelhos côncavos e convexos, constatou-se a necessidade de se usarem, outros materiais além dos indicados no caderno para poder realizá-lo. Sugerimos adaptações às atividades de leitura apresentadas no tema Universo, indicando outros textos como referências que poderiam ser mais adequados do que o livro "O guia do mochileiro das galáxias". Construímos um espectroscópio com papel cartão e, empregando um CD, pudemos observar as linhas associadas à luz emitida por lâmpadas com gás de sódio e mercúrio na apresentação do modelo de Bohr. Introduzimos o uso de simuladores de modelos físicos, em particular o desenvolvido pela Universidade do Colorado (PhET..., 2015), iniciativa muito bem recebida pelos professores a tal ponto de alguns deles comentarem, no decorrer do curso, que passaram a utilizá-lo em suas aulas. Em suma, consideramos que conseguimos desenvolver o curso a partir das demandas trazidas pelos professores, viabilizando uma leitura crítica e propositiva com relação ao currículo oficial.

\section{Considerações finais}

O currículo oficial do Estado de São Paulo é um conjunto de textos institucionalizados, elaborados a partir de uma formação ideológica que concebe o sistema educativo de determinada maneira, tentando inculcar um ideal de educação escolar que, à luz da crítica, pode ser sempre questionado: Por quê? Para quem? Para quê? Como? A natureza persuasiva e autoritária, sob a égide da cientificidade, foi evidenciada nos discursos veiculados nos documentos oficiais que compõem o currículo. Além do ideal formativo compartilhado por seus autores na posição de representantes do Estado, há um investimento financeiro elevado para a produção e distribuição dos cadernos para todos os alunos da rede, e este é mais um motivo pelo qual é de se esperar que o Estado estabeleça meios para que seu currículo seja adotado. Mas, este movimento encontra resistências nas leituras que os protagonistas dos processos de ensino e aprendizagem fazem a partir de suas posições, resultando nas transformações pelas quais passam as propostas curriculares conforme descritas por Gimeno Sacristán.

Ações de formação continuada parecem ser mais frutíferas quando se consideram, efetivamente, os saberes experienciais dos professores destacados por Tardif e Lessard (2011), criando espaços para o diálogo, as dúvidas e inquietações relacionadas à profissão. Ou seja, tentando tornar o discurso pedagógico menos autoritário e um pouco mais polêmico, pois, como frisa Orlandi (2009, p. 36): "Não acredito que apenas não se esteja dizendo o suficiente. Não está se ouvindo o necessário”. Problematizar as prescrições curriculares e as práticas pode colaborar para um salutar deslocamento em relação às posições cristalizadas no discurso pedagógico em que professores e alunos são geralmente situados. Além disso:

Para permitir uma participação ativa dos docentes, o currículo não poderia ser concebido como propostas que automaticamente podem ser transferidas para a prática sem modificações de suas potencialidades, mas como hipó- 
tese, como tentativas a serem ensaiadas pelos professores em suas classes. (GIMENO SACRISTÁN, 2000, p. 176)

Ouvir de fato os professores acerca dessas tentativas e de outras iniciativas suas, forneceria subsídios para a construção de currículos que não fossem estanques, mas que estivessem em constante evolução. Cabe observar que, desde sua concepção em 2008, os cadernos oficiais não têm sido revisados e renovados nas situações de aprendizagem e atividades recomendadas, sendo essencialmente os mesmos por vários anos.

E, se não forem viabilizadas aos professores condições para que exerçam e desenvolvam sua criticidade, não nos parece razoável esperar que as escolas consigam formar cidadãos críticos e ativos na transformação da sociedade, como é exaustivamente repetido nos objetivos educacionais em documentos oficiais. Tais condições envolvem, inequivocamente, a formação continuada dos docentes, não por meio de ações que os coloquem na posição passiva de receberem mais prescrições daqueles que se consideram detentores das soluções dos problemas educacionais e sabedores das suas "reais" necessidades, mas por meio de uma postura de parceria no levantamento das questões e busca por soluções que estimule o estabelecimento de relações menos hierarquizadas entre os interlocutores na reconstrução do discurso pedagógico.

\section{Referências}

BOGDAN, R. C.; BIKLEN, S. K. Investigação qualitativa em educação: uma introdução à teoria e aos métodos. Porto: Porto Editora, 1994.

BOURDIEU, P. A economia das trocas simbólicas. São Paulo: Perspectiva, 1974.

BRANDÃO, H. H. N. Introdução à análise do discurso. 2. ed. rev. Campinas: Editora da Unicamp, 2004.

BRASIL. Ministério da Educação. Secretaria de Educação Básica. Orientações curriculares para o ensino médio: ciências da natureza, matemática e suas tecnologias. Brasilia, 2006.

- Ministério da Educação. Secretaria de Educação Média e Tecnológica. Parâmetros curriculares nacionais: ciências da natureza, matemática e suas tecnologias. Brasília, 2000.

PCNs+ ensino médio: orientações educacionais complementares aos parâmetros curriculares nacionais - ciências da natureza, matemática e suas tecnologias. Brasília, 2002.

CAPELOTO, L. R.; ZANCUL, M. C. S. Uma reflexão teórica sobre contribuições dos PCN de ciências naturais para a prática pedagógica nos anos iniciais do ensino fundamental. In: ZANCUL, M. C. S.; MONTEIRO, D. C. (Org.). Práticas pedagógicas em diferentes componentes curriculares. São Paulo: Cultura Acadêmica, 2012, p. 149-166.

DELIZOICOV, D.; ANGOTTI, J. A. Física. São Paulo: PUCSP; Brasília: MEC, 1988. (Projeto diretrizes gerais para o ensino do $2^{\circ}$ grau - núcleo comum).

FERREIRA, M. L. Teoria e prática na formação docente: base e consolidação do trabalho pedagógico na práxis social. In: FERREIRA, N. R. S.; SILVA, M. C. P. (Org.). Formação docente: práticas, textos e contextos. Belo Horizonte: Fundac, 2008. p. 93-120. 
GATTI, B. A. Formação de professores e carreira: problemas e movimentos de renovação. 2. ed. Campinas: Autores Associados, 2000.

GIMENO SACRISTÁN, J. O currículo: uma reflexão sobre a prática. 3. ed. Porto Alegre: Artmed, 2000.

MAINGUENEAU, D. Novas tendências em análise do discurso. 3. ed. Campinas: Pontes: Editora da Unicamp, 1997.

NÓVOA, A. (Org.). Os professores e sua formação. Lisboa: Dom Quixote, 1992.

ORLANDI, E. P. Análise de discurso: princípios e procedimentos. 9. ed. Campinas: Pontes, 2010.

. Discurso, imaginário social e conhecimento. Em Aberto, Brasília, v. 14, n. 61, p. 53-59, 1994.

Pontes, 2009.

A linguagem e seu funcionamento: as formas do discurso. 5. ed. Campinas:

PhET: interactive simulations. Boulder: University of Colorado, 2015. Disponível em:

$<$ https://phet.colorado.edu/en/simulations/category/physics>. Acesso em: 3 nov. 2015.

SÃO PAULO (ESTADO). Secretaria Estadual de Educação. Currículo do estado de São

Paulo: ciências da natureza e suas tecnologias. São Paulo, 2010. Disponível em: <http:// www.rededosaber.sp.gov.br/portais/Portals/43/Files/CNST.pdf>. Acesso em: 10 nov. 2015.

SILVA, T. T. Documentos de identidade: uma introdução às teorias do currículo. 3. ed. Belo Horizonte: Autêntica, 2010.

TARDIF, M.; LESSARD, C. O trabalho docente: elementos para uma teoria da docência como profissão de interações humanas. 6. ed. Rio de Janeiro: Vozes, 2011.

WATANABE-CARAMELLO, G.; ZANOTELLO, M.; PIRES, M. O. C. A perspectiva freireana na formação continuada de professores de física. Alexandria: revista de educação em ciência e tecnologia, Florianópolis, v. 7, n. 2, p. 51-72, 2014.

Artigo recebido em 09/03/2015. Aceito em 06/07/2015.

Endereço para contato:

Rua Abolição, s/n, Vila São Pedro, CEP 09210-180, Santo André, SP, Brasil. 